\title{
KELAYAKAN FINANSIAL USAHA PENGGILINGAN PADI DI KECAMATAN TANJUNG LAGO BANYUASIN SUMATERA SELATAN
}

\section{FINANCIAL FEASIBILITY OF RICE MILLING BUSINESS IN TANJUNG LAGO BANYUASIN DISTRICT, SOUTH SUMATRA}

\author{
Elisa Wildayana* \\ Jurusan Sosial Ekonomi, Fakultas Pertanian, Universitas Sriwijaya, Jln. Palembang-Prabumulih Km 32, \\ Kampus Indralaya, Ogan Ilir 30662, Sumatera Selatan, Indonesia
}

Received: 24th December 2015; Revised: 24th February 2016 ; Accepted: 24th February 2016

\begin{abstract}
ABSTRAK
Tujuan penelitian ini adalah untuk menganalisis kelayakan finansial usaha penggilingan padi (Rice Milling Unit, RMU) di Kecamatan Tanjung Lago Banyuasin Sumatera Selatan. Metode penelitian adalah survai dengan penentuan 3 (tiga) RMU yang dipilih secara purposive. Hasil penelitian menunjukkan bahwa usaha RMU layak dilaksanakan secara finansial karena nilai Gross B/C > 1,32-1,52, NPV sebesar Rp 143,64-160,77 juta dan IRR berkisar 39,21-41,91\%. RMU menjadi tidak layak dilaksanakan jika terjadi peningkatan biaya operasional $>50 \%$. Tiga komponen dominan yang mempengaruhi sensitivitas analisis, yaitu kenaikan upah tenaga kerja, kenaikan harga bahan bakar solar, dan penurunan jumlah giling tahunan.
\end{abstract}

Kata kunci: kelayakan; finansial; usaha penggilingan padi; tanjung lago; banyuasin

\begin{abstract}
This research aimed to analyze the financial feasibility of the Rice Milling Unit (RMU) in Tanjung Lago Banyuasin, South Sumatra. Three RMUs were purposively selected and intensively surveyed. The results showed that the RMU business was financially feasible because Gross B/C > 1.32-1.52, NPV values were Rp 143.64-160.77 Millions, IRR values were 39.21-41.91\%. The three components in operational costs, which are very dominant changed, consist of labor costs, diesel fuel price, and milled annual total.
\end{abstract}

Keywords: feasibility; financial; rice milling unit; tanjung lago; banyuasin

\section{Pendahuluan}

Beras adalah komoditas strategis dan pangan pokok bangsa Indonesia. Konsumsi beras terus meningkat sejalan dengan meningkatnya jumlah penduduk karena beras merupakan sumber utama karbohidrat bagi penduduk Indonesia. Upaya pemerintah untuk mengerem laju konsumsi beras dengan keanekaragaman pangan lokal, namun tampaknya setiap tahun selalu mengalami kenaikan. Semakin maraknya beras impor di pasar-pasar domestik berdampak pada produksi beras dalam negeri memiliki daya saing yang rendah. Untuk mendapatkan beras tersebut harus melalui tahapan-tahapan yang sistematis, sehingga memperoleh hasil yang

"Penulis Korespondensi.

E-mail: wildayana.elisa@yahoo.com

Telp: +62-711-820933, HP: +62-8127338950 optimal (Wildayana dan Armanto, 2002, 2009, Armanto, 2014).

Agar beras produksi dalam negeri mampu bersaing di pasar global, maka mutu dan efisiensi proses pengolahan beras harus ditingkatkan dan banyak hal yang perlu diperbaiki, antara lain meminimalkan tingkat kehilangan gabah baik saat pemanenan, perontokan dan saat penggilingan (Moten dan Thron, 2013). Faktorfaktor lain yang mempengaruhi mutu beras, yaitu: (1) mutu gabah, (2) teknik pengeringan dan penggilingan, dan (4) sumberdaya manusia (Christanti et al., 2006, Bautista dan Siebenmorgen, 2002).

Hasil panen yang dihimpun dalam lumbung kelompok dijual dalam bentuk beras berkualitas dengan harga yang lebih tinggi bukan dalam bentuk gabah. Harga yang fluktuatif, besarnya kehilangan hasil dan mutu yang rendah cenderung tidak memberikan insentif kepada 
petani dan perlu segera dicari solusinya (Wildayana, 2003a, 2003b). Kehilangan hasil panen mencapai 20,5\% dengan mutu beras yang dihasilkan umumnya sangat rendah yang dicirikan oleh banyak beras patah (> $15 \%$ ) dengan rasa, warna yang kurang baik, selanjutnya harga gabah ditingkat petani belum dapat memperbaiki tingkat pendapatan (Perretti et al., 2003, Wildayana, 2015).

Surplus padi di Kecamatan Tanjung Lago merupakan peluang bagi petani dan penggilingan padi (Rice Milling Unit, RMU) dalam peningkatan pendapatan melalui peningkatan kualitas beras. Pangsa pasar tersedia, hanya saja petani terkendala pada pengolahan padi menjadi beras yang berkualitas. RMU adalah kegiatan terakhir dari seluruh tahapan budidaya padi yang dimulai dari penanaman, perawatan tanaman, panen dan pascapanen. Tahap-tahapan penggilingan meliputi pengadaan bahan baku, pengeringan, pemecah kulit, penyosohan, pengayakan, pemutihan, pengepakan, penyimpanan, distribusi dan pemasaran.

RMU diusahakan oleh pengusaha atau kelompok tani. Pengusahaan yang dilakukan oleh Koperasi Unit Desa (KUD) belum banyak berkembang karena menyangkut masalah investasi dan aspek manajemennya. RMU tersebut disewakan bagi petani untuk kebutuhan beras bagi konsumsi lokal. Pembayaran sewa dihitung berdasarkan hasil beras yang digiling.

Semakin meningkat ketergantungan petani pada RMU, maka pelayanan jasa RMU semakin berkembang. Tanpa perencanaan, pengawasan dan informasi serta analisis usaha yang tepat, hal tersebut dapat menimbulkan dampak negatif bagi sosial ekonomi masyarakat. Apalagi jika tidak diikuti kontrol pemerintah yang tegas melalui kebijakan. Walaupun banyak usaha RMU, namun penyebaran dan kelayakannya belum optimal.

Kondisi ini memerlukan evaluasi untuk menilai tingkat kebutuhan optimum, sehingga layak untuk beroperasi dan menguntungkan. Biaya RMU perlu diketahui pada tahap perencanaan dan pelaksanaan. Biaya RMU perlu dihitung untuk mengetahui kelayakan RMU tersebut dan biaya penggilingan akan dipakai sebagai patokan untuk menentukan harga jual jasa RMU pada konsumen (Sun dan Siebenmorgen, 1993).

Seiring dengan laju peningkatan konsumsi beras, maka produsen utama (petani) dan pengusaha lokal juga termotivasi untuk mengembangan usaha RMU. Oleh karena itu, analisis biaya yang tepat mengenai kelayakan finansial usaha RMU diharapkan dapat digunakan sebagai penunjang pengambilan keputusan dalam menentukan ongkos giling yang tepat agar tidak mengalami kerugian dan memproyeksikan keuntungan yang kontinyu untuk usaha RMU tersebut (Hua et al., 2006, Armanto et al., 2013). Tujuan penelitian ini adalah untuk menganalisis kelayakan finansial usaha RMU di Kecamatan Tanjung Lago Banyuasin Sumatera Selatan.

\section{Metode Penelitian}

Kegiatan penelitian ini dilaksanakan pada bulan Januari sampai April 2015. Lokasi penelitian adalah daerah sentra produksi padi di Kecamatan Tanjung Lago Kabupaten Banyuasin. Tiga RMU terpilih dilakukan secara purposive dan penentuan responden secara simple random sampling dengan kriteria responden bahwa RMU yang dikaji memiliki kesetaraan dalam volume, skala dan memiliki izin usaha. Hasil analisis data ditabulasikan dan dijelaskan secara deskriptif kuantitatif, khususnya untuk parameter finansial.

Pendapatan bersih usaha RMU berdasarkan pengolahan data dengan menggunakan formula matematis, yaitu: Keuntungan = Penerimaan Total - Biaya Total . Komponen biaya total terdiri atas Biaya Investasi dan Biaya Operasional. Biaya operasional adalah biaya yang secara total berubah secara proporsional dengan perubahan aktivitas dan dipengaruhi oleh jumlah produksi yang dihasilkan, akan tetapi biaya operasional per unit sifatnya konstan. Biaya Investasi adalah keseluruhan biaya tanpa terpengaruh oleh tingkat aktivitas.

Perhitungan analisis finansial adalah metode arus tunai berdiskonto dengan tingkat discount factor $15 \%$ per tahun. Parameter analisis finansial, antara lain: Net Present Value (NPV), Gross B/C, dan IRR (Pogue, 2004, Hartman dan Schafrick, 2004).

\section{a. Gross Benefit Cost Ratio (Gross B/C)}

Gross B/C secara matematis merupakan perbandingan nilai ekuivalen semua benefit terhadap nilai ekuivalen semua biaya. Kriteria pengambilan keputusan adalah dengan cara melihat nilai Gross B/C apakah lebih besar, sama atau lebih kecil dari satu. Jika Gross B/C $\geq 1$, maka investasi RMU layak (feasible), diterima dan jika Gross B/C < 1, maka investasi RMU tidak layak (not feasible). Rumus perhitungan nilai Gross B/C dapat dilakukan dengan menggunakan rumus sebagai berikut: 


$$
\text { GrossB/C }=\frac{\sum \text { PV Gross Benefits }}{\sum \text { PV GrossCosts }} \ldots \text {..(1) }
$$

\section{b. Perhitungan NPV (Net Present Value)}

NPV merupakan nilai RMU yang diperoleh berdasarkan selisih antara cash flow yang dihasilkan terhadap investasi yang dikeluarkan. NPV memerlukan data biaya investasi, biaya operasional, pemeliharaan dan perkiraan benefit dari RMU yang direncanakan.

$$
\text { NPV }=\text { PV Benefit }- \text { PV Cost }
$$

Dimana :

$$
\begin{array}{ll}
\text { NPV } & =\text { Net Present Value } \\
\text { PV Benefit } & =\text { Faktor diskonto } \mathrm{x} \text { Benefit } \\
\text { PV Cost } & =\text { Faktor diskonto } \mathrm{x} \text { Cost }
\end{array}
$$

Kriteria NPV yaitu :

1) NPV > 0, berarti usaha RMU layak (feasible) untuk dilaksanakan.

2) NPV < 0, berarti sampai dengan $t$ tahun investasi usaha RMU tidak tidak layak untuk dilaksanakan.

3) $\mathrm{NPV}=0$, berarti tambahan manfaat sama dengan tambahan biaya yang dikeluarkan.

\section{c. Internal Rate of Return (IRR)}

IRR adalah indikator tingkat efisiensi suatu investasi untuk menentukan apakah investasi dilaksanakan atau tidak. Acuan yang digunakan bahwa investasi yang dilakukan harus lebih tinggi dari Minimum Acceptable Rate of Return. Minimum Acceptable Rate of Return adalah laju pengembalian minimum dari suatu investasi yang boleh dilakukan oleh investor.

$$
\mathrm{IRR}=\mathrm{i}_{1}+\frac{\mathrm{NPV}_{1}}{\mathrm{NPV}_{1}-\mathrm{NPV}_{2}}\left(\mathrm{i}_{2}-\mathrm{i}_{1}\right) \ldots
$$

Dimana: IRR = Internal Rate of Return

$\mathrm{i}_{1}=$ Faktor diskonto tertinggi yang sudah memberi NPV positif

$\mathrm{i}_{2}=$ Faktor diskonto tertinggi yang masih memberi NPV negatif

$\mathrm{NPV}_{1}=$ Net Present Value positif

$\mathrm{NPV}_{2}=$ Net Present Value negatif

Kriteria IRR yaitu :

IRR > Discount Factor Rate berarti usaha RMU layak dilaksanakan;

$\mathrm{IRR}=$ Discount Factor Rate berarti usaha RMU akan balik modal;

IRR < Discount Factor Rate berarti usaha RMU tidak layak dilaksanakan.

\section{d. BEP (Break Event Points)}

BEP (Titik Impas) adalah saat dimana jumlah penerimaan sama dengan jumlah total biaya yang dikeluarkan. Analisis sensitivitas dilakukan apabila terjadi suatu kesalahan pendugaan suatu nilai biaya atau manfaat dan kemungkinan terjadi perubahan suatu unsur harga pada saat RMU dilakukan.

\section{Hasil dan Pembahasan}

Salah satu sentra produksi beras di Kabupaten Banyuasin adalah Kecamatan Tanjung Lago yang berlokasi sekitar $15 \mathrm{~km}$ Utara dari kota Palembang dan berjarak $45 \mathrm{~km}$ menuju ke Pelabuhan Laut Internasional Tanjung Api-api (TAA). Kondisi jaringan jalan belum optimal dan kurangnya fasilitas pengolahan hasil, termasuk penggilingan padi menyebabkan arus perdagangan beras menjadi kurang optimal.

Kontribusi sektor pertanian terhadap Produk Domestik Regional Bruto (PDRB) tahun 2012 mencapai 30,35 \% dan merupakan kontribusi terbesar terhadap kondisi perekonomian di Kabupaten Banyuasin. Produksi padi pada tahun 2012 mencapai 882.597 ton yang dihasilkan dari 200.980 ha luas panen dengan tingkat produktivitas sebesar 4,39 ton/ha. Tingkat produksi padi rata-rata mencapai 2-3 ton GKG (Gabah Kering Giling)/ha dan hanya satu kali tanam (IP 100) dalam setahun (BPS Provinsi Sumatera Selatan, 2012).

\subsection{Kondisi Umum Lokasi Penelitian}

Kecamatan Tanjung Lago adalah sentra produksi beras karena sekitar $40,33 \%$ total luas wilayahnya merupakan lahan sawah pasang surut, 54,97 \% sebagai lahan non pertanian termasuk hutan rakyat, dan $4,73 \%$ untuk permukiman dan fasilitas umum lainnya termasuk jalan.

Produksi padi di lokasi penelitian sulit untuk dibawa ke pasar, sehingga petani hanya menerima sedikit nilai tambah, dan kebutuhan bahan yang diperlukan dari pasar juga sulit dibawa ke lokasi penelitian, sehingga berdampak pada harga barang yang tinggi. Semuanya ini disebabkan kondisi jaringan jalan yang kurang memadai untuk sarana transportasi barang dan jasa dan keberadaan RMU yang terbatas.

RMU dapat menghasilkan beras dengan mutu baik dan rendemen beras yang tinggi (63-67 $\%$ ), memproses gabah menjadi beras dalam satu kali proses, kapasitas giling berkisar 0,2-1,0 ton/jam dan kadar air gabah $15 \%$ basis basah. 
RMU adalah mesin yang terintegrasi secara kompak dan bekerja secara harmonis dengan tenaga penggerak tunggal. Mesin-mesin yang digunakan dalam RMU adalah mesin pemecah kulit/sekam (huller atau husker), mesin pemisah gabah dan beras pecah kulit (brown rice separator), mesin penyosoh atau mesin pemutih (polisher), mesin pengayak bertingkat (sifter), mesin atau alat bantu pengemasan (timbangan dan penjahit karung). Kesemua fungsi tersebut dikemas dalam satu mesin yang kompak dan padat, sehingga praktis dan mudah digunakan. RMU berkembang pesat dalam 5 (lima) tahun terakhir ini, kepesatan usaha RMU didukung oleh kebijakan Pemkab Banyuasin yang kondusif dalam peningkatan produktivitas padi. Persaingan usaha RMU ini bersifat positif dan kompetitif, sehingga harga yang ditawarkan cukup menguntungkan kedua belah pihak. Variasi kapasitas, jenis dan karakteristik RMU disajikan pada Tabel 1.

Tabel 1. Spesifikasi teknis RMU di Kecamatan Tanjung Lago Banyuasin.

\begin{tabular}{clccc}
\hline No & Spesifikasi Mesin RMU */ & RMU P & RMU R & RMU S \\
\hline 1 & Pemilik & Pengusaha & Petani & Pengusaha \\
2 & RPM (Rotary per Minute $)$ & 1.100 & 1.100 & 1.100 \\
& & 1800 & 700 & 900 \\
3 & Model & HW60AN & ECH60AN & ECH60AN \\
& \multirow{2}{*}{ Kapasitas/jam } & N70 & N60 & RD160H \\
& & $13 \mathrm{HP}$ & $13 \mathrm{HP}$ & $13 \mathrm{HP}$ \\
& $10 \mathrm{KW}$ & $8 \mathrm{KW}$ & $10 \mathrm{kw}$ \\
\hline
\end{tabular}

Keterangan : */Semua mesin RMU bermerk Yanmar/Kubota dan berfungsi sebagai pengupas/penyosoh

\subsection{Kelayakan RMU}

Komponen biaya yang dipertimbangkan dalam kelayakan RMU adalah: (1) Biaya investasi, yaitu investasi awal yang meliputi mesin diesel, penyosok dan pencacah, gedung/gudang pemroses termasuk lantai penjemuran, peralatan pelengkap dan lain-lain, (2) Biaya operasional adalah biaya yang dikeluarkan setiap tahun terdiri dari biaya pemeliharaan (service dan maintenance), bunga bank, pajak/retribusi dan peralatan habis pakai (karung, ember, tali, pisau, lampu; biaya yang dikeluarkan untuk operasional yang terdiri dari BBM (solar), minyak pelumas (oli), listrik dan operator mesin RMU. Besarnya biaya pada ketiga
RMU disajikan pada Tabel 2. Pendapatan bersih merupakan selisih dari penerimaan dengan biaya. Pada tahun ke 0 dan 1 akan bernilai negatif. Hal ini karena pada awal investasi butuh biaya tinggi dan sampai dengan tahun 1 belum berproduksi, sehingga nilai negatif, dan pada tahun ke 2 sampai dengan tahun ke lima sesuai dengan nilai ekonomis mesin RMU; nilai bangunan, gudang dan alat bantu lainnya. Gross B/C untuk semua RMU menunjukkan nilai Gross B/C sebesar 1,52 untuk RMU P, 1,32 untuk RMU R dan 1,42 untuk RMU S. Semua nilai Gross B/C bernilai > 1, sehingga dapat disimpulkan bahwa semua RMU layak dilakukan dan memberikan untung bagi petani.

Tabel 2. Analisis kelayakan finansial RMU di Kecamatan Tanjung Lago

\begin{tabular}{lccc}
\hline \multicolumn{1}{c}{ Parameter finansial } & RMU P $* * /$ & RMU R & RMU S \\
\hline Biaya Investasi (Rp juta) & 11,74 & 9,82 & 10,87 \\
Biaya operasional (Rp juta) & 35,99 & 32,89 & 34,99 \\
Total Biaya (Rp juta) & 47,73 & 42,71 & 45,86 \\
Pendapatan (Rp juta) & 72,55 & 56,38 & 65,12 \\
NPV (Rp juta) & 160,77 & 143,64 & 152,28 \\
Gross B/C & 1,52 & 1,32 & 1.42 \\
IRR Aktual (\%) & 41,91 & 39,21 & 40,71 \\
BEP (ton GKG) */ & 35,57 & 35,57 & 35,57 \\
Kriteria Penilaian & Layak & Layak & Layak \\
\hline Prioritas Kelayakan & 1 & 3 & 2 \\
\hline
\end{tabular}

Keterangan : */ GKG: Gabah Kering Giling, IRR estimated $15 \%$ (bunga bank BNI)

Perhitungan dengan investasi pada $\mathrm{T}_{0}-\mathrm{T}_{5}(5$ tahun $)$

**/ RMU P dan RMU S dikelola oleh pengusaha, dan RMU R dikelola oleh petani 
NPV memberikan nilai positif, yaitu RMU P Rp 160,77 juta; RMU R Rp 143,64 juta dan RMU S sebesar Rp Rp 152,28 juta. Hal ini berarti bahwa investasi usaha RMU selama 5 (lima) tahun memberikan keuntungan masing-masing sebesar Rp 160,77 juta; Rp 143,64 juta dan Rp 152,28 juta. Nilai IRR adalah 41,91\% untuk RMU P; RMU R 39,21 \% dan RMU S 40,71\%. Dengan nilai indikator IRR $>15 \%$, maka usaha tiga RMU tersebut layak untuk dilaksanakan.

BEP usaha RMU sebesar 140 jam $(35,37$ ton GKG). Agar RMU tidak merugi, maka RMU harus beroperasi minimal selama 140 jam (menggiling padi sebanyak 35,37 ton GKG). Dengan indikator Gross B/C, NPV, IRR, BEP dan kondisi normal, maka semua RMU layak dilakukan dan menguntungkan.

\subsection{Analisis Kepekaan (Sensitivity Analysis)}

Analisis kepekaan dilakukan terhadap kenaikan biaya operasional yang terdiri dari peningkatan upah tenaga kerja dan harga solar serta penurunan jumlah giling tahunan Tabel 3 . Adanya peningkatan produksi, penawaran akan bertambah, diikuti peningkatan biaya operasional. Inflasi terhadap harga barang juga mempengaruhi terhadap peningkatan biaya operasional.

Analisis sensitivitas dilakukan pada suku bunga Bank $15 \%$ dapat dilihat bahwa perubahan komponen biaya operasional, yaitu peningkatan upah tenaga kerja dan harga bahan bakar solar serta penurunan jumlah giling tahunan sampai 50 $\%$, ternyata tidak berpengaruh yang berarti terhadap RMU. Batas toleransi kenaikan biaya operasional maksimum adalah $50 \%$. Dengan batas toleransi sebesar $50 \%$, RMU masih layak untuk dijalankan. Jika terjadi kenaikan biaya operasional > $50 \%$ (melebihi batas toleransi), maka RMU ini tidak layak lagi untuk dijalankan karena akan mengalami kerugian (Tabel 3).

Faktor yang lebih sensitif terhadap kelayakan finansial RMU adalah penurunan jumlah giling tahunan. Agar RMU tetap layak untuk dijalankan, maka kestabilan harga jual beras harus dipertahankan pada kondisi normal. Peran pemerintah sangat penting dalam hal penyeimbangan harga jual beras yang dihasilkan dengan melalui kebijakan harga terendah, agar harga jual beras yang terjadi di pasaran tidak jauh melenceng dari harga yang ditetapkan oleh pemerintah.

Tabel 3. Analisis sensitivitas terhadap kenaikan biaya operasional */

\begin{tabular}{|c|c|c|c|c|c|}
\hline \multirow{2}{*}{$\begin{array}{l}\text { Kenaikan Biaya } \\
\text { Operasional (\%) }\end{array}$} & \multirow{2}{*}{$\begin{array}{c}\text { NPV } \\
\text { (Rp juta) }\end{array}$} & \multirow{2}{*}{$\begin{array}{l}\text { IRR } \\
(\%)\end{array}$} & \multirow{2}{*}{$\begin{array}{c}\text { GROSS } \\
\text { B/C }\end{array}$} & \multicolumn{2}{|c|}{ BEP } \\
\hline & & & & Jam & Ton GKG \\
\hline 0 & 160,77 & 41,91 & 1,52 & 140 & 35,57 \\
\hline 25 & 151,98 & 38,69 & 1,47 & 140 & 35,57 \\
\hline 50 & 133,78 & 34,98 & 1,14 & 140 & 35,57 \\
\hline 75 & $-45,67$ & 14,32 & 0,97 & 140 & 35,57 \\
\hline
\end{tabular}

Keterangan : */ Biaya operasional yang menentukan perubahan dominan adalah kenaikan harga solar, upah tenaga kerja dan penurunan jumlah giling.

\section{Kesimpulan}

Berdasarkan hasil dan pembahasan penelitian, maka dapat disimpulkan hal-hal sebagai berikut:

Usaha RMU memerlukan total biaya berkisar Rp 42,71-47,73 juta dan jasa pemanfaatan RMU dikenakan imbalan sebesar $1: 10$, artinya untuk setiap $10 \mathrm{~kg}$ beras yang dihasilkan, dikenakan biaya giling sebesar $1 \mathrm{~kg}$ beras.

Nilai Gross B/C berkisar 1,32-1,52 dengan NPV sebesar Rp 143,74-160,77 juta. Nilai IRR sebesar 39,21-41,91. BEP (Titik Impas) RMU sebesar 140 jam (35,37 ton GKG). Agar RMU tidak merugi, maka RMU harus beroperasi minimal 140 jam atau menggiling padi sebanyak 35,37 ton GKG. Usaha RMU layak dilaksanakan secara finansial karena nilai Gross B/C > 1, NPV positif dan > 1 dan IRR > $15 \%$ (Bank Discount Rate).

RMU menjadi tidak layak dilaksanakan jika terjadi peningkatan biaya operasional $>50$ $\%$. Tiga komponen dominan yang mempengaruhi sensitivitas analisis, yaitu kenaikan upah tenaga kerja, kenaikan harga bahan bakar solar, dan penurunan jumlah giling tahunan.

Berdasarkan data lapangan, sebagian besar peralatan RMU sudah melampaui umur ekonomis, sehingga meningkatan biaya operasional yang nyata. Oleh karena itu, perlu direkomendasikan untuk melakukan peremajaan alat-alat dan mesin agar dapat menekan biaya operasional. Selain itu, hasil penelitian merekomendasikan agar menggunakan RMU dengan RPM (Rotary per Minute) yang tinggi. 


\section{Daftar Pustaka}

[1]. Armanto, M.E. 2014. Spatial Mapping for Managing Oxidized Pyrite $\left(\mathrm{FeS}_{2}\right)$ in South Sumatra Wetlands, Indonesia. Journal of Wetlands Environmental Managements. Vol 2(2); 6-12, October 2014. ISSN: 23545844. Indexed in DOAJ (Directory of Open Access Journals). Web-link: http://ijwem.unlam.ac.id/index.php/ijwem.

[2]. Armanto, M.E., M.A. Adzemi, E. Wildayana and M.S. Imanudin. 2013. Land Evaluation for Paddy Cultivation in the Reclaimed Tidal Lowland in Delta Saleh, South Sumatra, Indonesia. Journal of Sustainability Science and Management. Vol 8(1):32-42. June 2013. ISSN 18238556. (SCOPUS, Google Scholar and DOAJ indexes). Web-link: http://jssm.umt.edu.my/files/2013/07/4w.p df.

[3]. Bautista, R.C. and T.J. Siebenmorgen. 2002. Evaluation of Laboratory Mills for Milling Small Samples of Rice. Applied Engineering in Agriculture, Vol 18(5): 577-583.

[4]. BPS Provinsi Sumatera Selatan. 2012. Statistik Sumatera Selatan Tahun 2011. Palembang. Biro Pusat Statistik, Provinsi Sumatera Selatan.

[5]. Christanti, D., A. Mulyana dan Elisa Wildayana. 2006. Faktor-faktor yang Mempengaruhi Produksi Beras Varietas Lokal Mutu Rendah dan Mutu Serta Hubungannya dengan Pendapatan Petani. Journal of AGRIPITA Vol III(3): 185-191, December 2006. ISSN: 1829-555X.

[6]. Hartman, J.C. and I.C. Schafrick. 2004. The Relevant Internal Rate of Return. The Engineering Economist Vol 49(2): 139158.

[7]. Hua, N., R. Bengtson, R., Schramm, T. Patel, T. Walker and M. Lima. 2006. Optimization of Yield and Quality Parameters for the Cocodrie Rice Variety as a Function of Harvest Time. Applied Engineering in Agriculture, Vol 22(1): 9599.

[8]. Moten, J. and C. Thron. 2013. Improvements on Secant Method for Estimating Internal Rate of Return, International Journal of Applied
Mathematics and Statistics 42:12, http://www.ceser.in/ceserp/index.php/ijam as/article/view/1929.

[9]. Perretti, G., E. Miniati, L. Montanari and P. Fantozzi. 2003. Improving the Value of Rice by-Products by SFE. Journal of Supercritical Fluids, Vol 26: 63-71.

[10]. Pogue, M. 2004. Investment Appraisal: A New Approach. Managerial Auditing Journal. Vol. 19(4): 565-570.

[11]. Sun, H. and T.J. Siebenmorgen. 1993. Milling Characteristics of Various Rough Rice Kernel Thickness Fractions. Journal of Cereal Chemistry, Vol 70(6): 727-733.

[12]. Wildayana, Elisa and M.E. Armanto. 2002. Economic Analysis of Forest for Upland Farming in South Sumatra, Indonesia. Journal of Environment \& Natural Resources Management, Vol 22(1):53-62, 2002. ISSN. 0216-2717.

[13]. Wildayana, Elisa dan M.E. Armanto. 2009. Dampak Financial Kehilangan Hara ke Atmosfir Akibat Kebakaran Hutan dan Lahan. Jurnal Habitat Vol. XX (2): 81-88, Agustus 2009. ISSN 0853-5167.

[14]. Wildayana, Elisa. 2003a. Karakter dan Valuasi Ekonomi Konversi Lahan Alangalang menjadi Lahan Pertanian. Jurnal Pengelolaan Lingkungan \& SDA 1(2):7379, September 2003. ISSN. 1693-0391.

[15]. Wildayana, Elisa. 2003b. Valuasi Ekonomi Konversi Hutan untuk Usahatani Lahan Kering. Jurnal Pengelolaan Lingkungan \& SDA 1(1):49-58, Maret 2003. ISSN. 16930391.

[16]. Wildayana, Elisa. 2015. Dampak Krisis Global Terhadap Pengeluaran Konsumsi Rumah Tangga Petani Plasma PIR BUN Kelapa Sawit di Kabupaten Muara Enim. Prosiding Seminar Nasional dalam Rangka Dies Natalis ke-52 FP Universitas Sriwijaya, Palembang, Indonesia, 05 November 2015. 